\title{
Manejo Multidisciplinario de Rinosinusitis Bacteriana Aguda posterior a elevación de Seno Maxilar. Reporte de Caso Rehabilitado a tres años de seguimiento.
}

\section{Multidisciplinary management of Acute Bacterial Rhinosinusitis after Maxillary Sinus Lift. Three years follow-up: case report.}

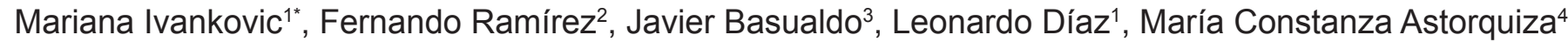

1. Práctica Privada. Chile

2. Profesor Adjunto, Programa de Especialización en Implantología Buco Máxilo Facial. Escuela de Graduados, Facultad de Odontología, Universidad de Chile. Chile

3. Profesor Asistente, Programa de Especialización en Implantología Buco Máxilo Facial. Escuela de Graduados, Facultad de Odontología, Universidad de Chile. Chile.

4. Otorrinolaringologa Clínica las Condes. Chile.

* Correspondencia autor: Mariana Ivanković Silva | Dirección: Av. Santa María 0596. Providencia, Santiago, Chile. | Teléfono: +56 952440743 |

E-mail: ivankovic.mariana@gmail.com

Trabajo recibido el 16/05/2019.

Aprobado para su publicación el 11/08/2019.

\section{RESUMEN}

La cirugía de elevación de seno maxilar se considera como la técnica de aumento óseo más predecible. Sin embargo, no está exenta de complicaciones las cuales deben ser manejadas adecuadamente.

Se presenta un caso clínico rehabilitado, con un seguimiento de 3 años, en el cual se realizó un manejo multidisciplinario y resolutivo de complicaciones asociadas a la técnica quirúrgica de elevación de membrana sinusal vía ventana lateral.

Frente a una infección postoperatoria, como la presentada en el caso, hay que considerar iniciar un tratamiento antibiótico en el momento adecuado para impedir el agravamiento del cuadro clínico o un cambio de esquema en caso de resistencia antimicrobiana.

PALABRAS CLAVE:

Rinosinusitis; Elevación de seno maxilar; implantes dentales.

International Journal of Interdisciplinary Dentistry Vol. 13(1) 35-39, 2020.

\section{ABSTRACT}

Maxillary sinus lift surgery is considered the most predictable bone augmentation technique. However, this procedure is not without complications, which must be handled properly.

We present a rehabilitated clinical case, with a 3-year follow-up, in which a multidisciplinary and resolutive management of complications associated with the surgical technique of sinus lift procedure, using lateral window approach, was performed.

In case of postoperative infection, such as the one presented in this report, it is necessary to consider starting an antibiotic treatment at the adequate moment to prevent the aggravation of the illness or change the pharmacological treatment in case of antimicrobial resistance.

KEY WORDS:

Rhinosinusitis; Sinus Lift; Dental implants.

International Journal of Interdisciplinary Dentistry Vol. 13(1) 35-39, 2020.

\section{INTRODUCCIÓN}

Actualmente, la cirugía de elevación de seno maxilar se considera como la técnica de aumento óseo más predecible. Sin embargo, no está exenta de complicaciones, las cuales pueden ser intraoperatorias o postoperatorias ${ }^{(1)}$.

Las complicaciones intraoperatorias generalmente son resultado de dificultades quirúrgicas presentadas durante la ejecución del procedimiento, causadas por situaciones anatómicas complejas (membranas delgadas, tabiques intrasinusales, paredes laterales gruesas, muy delgadas o convexas, vasos sanguíneos presentes en el sitio de la osteotomía, entre otros), inadecuado diagnóstico local y/o sistémico o error del operador. La complicación intraoperatoria más frecuente es la perforación de la membrana sinusal| ${ }^{(2,3)}$, reportándose un amplio rango de prevalencia en la literatura, entre un $11 \%$ a un $56 \%{ }^{(4)}$.

Existen numerosas maniobras durante la cirugía de elevación sinusa que pueden poner en riesgo la membrana, tales como la elevación del colgajo, la preparación de la ventana lateral con instrumental rotatorio, la elevación de la membrana con instrumentos manuales, especialmente hacia medial o en proximidad a tabiques y al colocar el material de injerto, por una presión excesiva contra la membrana ${ }^{(1)}$. Una membrana sinusal intacta es esencial para la contención del injerto. En caso de perforación, se requiere mucho cuidado para finalizar con éxito el procedimiento. Esto se logra, mediante la elevación de la membrana alrededor de la perforación, liberando de este modo la tensión en el área perforada. El método más común para reparar una perforación pequeña es mediante una membrana de colágeno reabsorbible. Otras técnicas incluyen el uso de suturas y fibrina rica en plaquetas. Cuando la perforación es mayor a $5 \mathrm{~mm}$, se debe utilizar una membrana que mantenga su forma o que permanezca rígida a pesar de estar humedecida. Cuando la perforación es mayor a $10 \mathrm{~mm}$, la reparación es impredecible. Hay probabilidades de pérdida parcial o total del injerto hacia la cavidad sinusal, evento adverso que puede conducir a una obstrucción del ostium y a una rinosinusitis postoperatoria. Será necesario una reintervención para eliminar todo el 
material de injerto particulado. Si la reparación no parece quedar estable, es necesario detener el procedimiento para permitir la cicatrización de la membrana sinusal(5).

En relación a las complicaciones postquirúrgicas mayores, son relativamente infrecuentes, dentro de ellas se incluyen; infección del injerto, rinosinusitis postoperatoria, sangrado profuso, dehiscencia del colgajo, formación de fistula oro-antral, formación de inadecuado volumen óseo para instalación de implantes, pérdida del injerto como resultado de la ruptura de la membrana sinusal, exfoliación del material del injerto a través de la ventana sinusal, formación de quistes maxilares, migración de implantes dentro del injerto o de la cavidad sinusal propiamente tal y fracaso del implante. Las infecciones postoperatorias son relativamente infrecuentes, con rangos presentados en la literatura entre un $2 \%$ y $5,6 \%$, sin distinción entre infección sinusal o rinosinusitis y la asociada al injerto. Si existe sospecha de infección, el tratamiento debe efectuarse de manera oportuna, puesto que una infección sinusal puede progresar a una pansinusitis

El propósito de este trabajo es presentar un caso clínico rehabilitado con 3 años de seguimiento, en el cual se realizó un manejo multidisciplinario y resolutivo de complicaciones intra y postoperatorias asociadas a la técnica quirúrgica de elevación de seno maxilar.

\section{REPORTE DEL CASO}

Se presenta el caso de una paciente de género femenino de 44 años, ASAI. Desdentada total superior y parcial inferior. Con neumatizaciones de ambos senos maxilares y rebordes alveolares atróficos. Sin antecedentes de alergias, ni consumo de tabaco ni alcohol. Posterior al examen clínico y al análisis de los exámenes complementarios se planifica la cirugía reconstructiva del maxilar superior previo al tratamiento rehabilitador fijo implantosoportado (Figura 1).

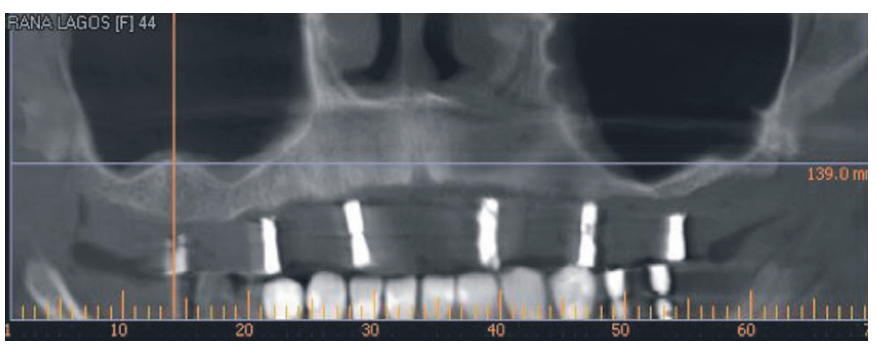

Figura 1. CB-CT: Se puede observar ambos senos maxilares neumatizados, radiolúcidos y rebordes alveolares atróficos.

La paciente fue sometida a una cirugía de reconstrucción de maxilar superior en sentido horizontal, a una elevación bilateral de senos maxilares (técnica de ventana lateral) y a la instalación de 4 implantes transicionales (Serson ${ }^{\circledast}$, Brasil) en forma simultánea. Al elevar el colgajo mucoperióstico del lado izquierdo se produjo una perforación de la membrana sinusal de diámetro entre 7 y $10 \mathrm{~mm}$. La perforación fue resuelta de acuerdo con los protocolos, con membrana de colágeno reabsorbible (Biomend ${ }^{\circledR}$ Extend $^{\circledR}$ Zimmer $^{\circledR}$, USA). Posteriormente se colocó el aloinjerto particulado (Purus ${ }^{\circledR}$ cortical, Zimmer ${ }^{\circledR}$, USA) combinado con concentrados plaquetarios entre la membrana y la pared inferior del seno. Se instalaron 4 implantes transicionales $(2.4 \times 10 \mathrm{~mm})$ en la premaxila (Figura 2 a y $2 \mathrm{~b}$ ).

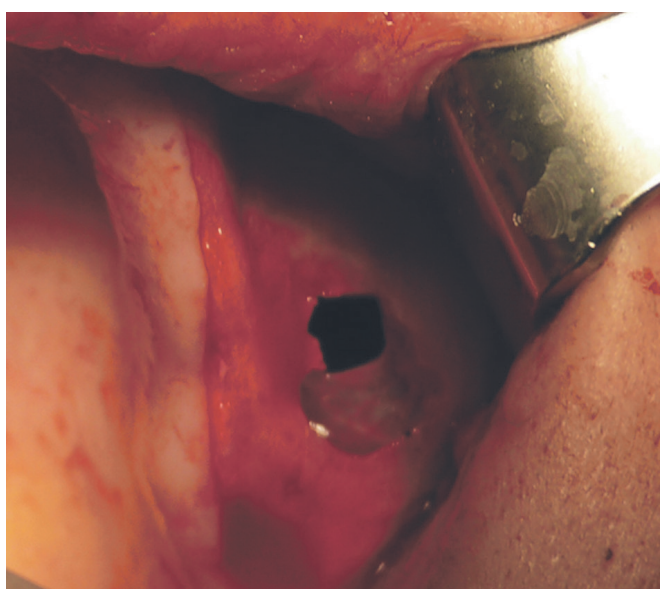

Figura 2. a.Perforación de membrana sinusal de seno maxilar izquierdo provocada al momento de desplazar el colgajo mucoperióstico.

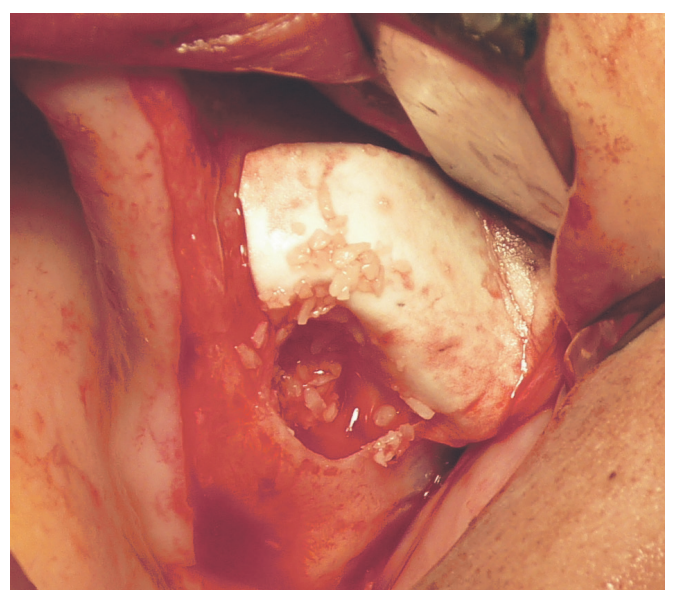

Figura 2. b.La perforación fue resuelta de acuerdo a los protocolos, con membrana de colágeno reabsorbible (Biomend extend, Zimmer, USA) para dar estabilidad al injerto.

La paciente inició premedicación antibiótica 24 hrs. antes de la cirugía y continuó con tratamiento con amoxicilina + ácido clavulánico 875/125 mg comprimidos dispersables (Clavinex Duo ${ }^{\circledR}$, Laboratorio Saval ${ }^{\circledR}$, Chile), 1 comprimido cada 12 horas por 10 días. 24 horas antes de la cirugía empezó con enjuagues con antiséptico oral de clorhexidina al $0.12 \%$ (Perio Aid $^{\circledR}$, Labotario Dentaid ${ }^{\circledR}$, España).

A la primera semana se tomó una radiografía $(R x)$ panorámica de control. Se observó el injerto en posición adecuada y ambos senos maxilares radiolúcidos.

Al día siguiente se conectó la prótesis removible superior a los implantes transicionales (Figura 3). A las dos semanas se realizó el retiro de suturas. Intraoralmente se observó cicatrización normal. A las 3 semanas de la cirugía al momento del examen la paciente relató obstrucción parcial de la fosa nasal izquierda, descarga nasal posterior y sensación de mal olor. No presentó dolor ni compromiso del estado general. Al examen intraoral se apreció reparación compatible con salud. Se solicitó Rx de cavidades paranasales, en la cual se observó velamiento del seno maxilar izquierdo, que permitió confirmar la hipótesis diagnóstica de Rinosinusitis maxilar izquierda aguda. Se inició la terapia antibiótica empírica inicial con amoxicilina + ácido clavulánico (875/125 mg cada 12 horas) por 10 días, Oximetazolina (Oxilin ${ }^{\circledR}$, Laboratorio Pasteur ${ }^{\circledR}$, Chile) 3 veces al día por 5 días, solución isotónica de agua de mar (Fisiomar ${ }^{\circledR}$, Laboratorio Pasteur ${ }^{\circledR}$, Chile) previo al Oxilin nasal y Paracetamol (1 $\mathrm{gr}$ cada 8 horas) e Ibuprofeno ( $400 \mathrm{mg}$ cada 8 horas) por 3-4 días en caso de dolor. En los días siguientes continuó con secreciones nasales fétidas y relató descargas nasales posteriores. Al cuarto día de inicio del cuadro relata cambio de la secreción a un tipo más verdeacuoso. Al sexto día, durante el examen intraoral presentó supuración al presionar el reborde superior izquierdo, compatible con fístula oro-antral y dolor leve a la palpación de dicha área. Se confirma el diagnóstico de Rinosinusitis Maxilar Bacteriana Aguda y se decide derivar al especialista en Otorrinolaringología.

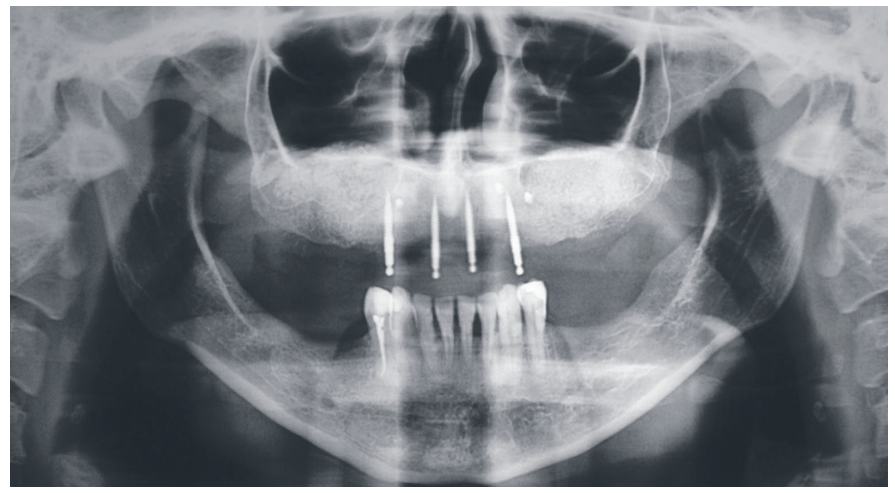

Figura 3. Radiografía panorámica de control a la primera semana. Se puede observar el injerto en posición adecuada y ambos senos maxilares radiolúcidos.

Al octavo día la paciente acude al médico especialista el cual decide cambiar la terapia antibiótica a Moxifloxacino (Moxaval ${ }^{\circledR}$, Laboratorio 
Saval ${ }^{\circledR}$, Chile), 1 comprimido de $400 \mathrm{mg}$ al día por 10 días, suspender la Oximetazolina y mantener el Fisiomar. Solicita una tomografía axial computarizada (TAC) de Cavidades Paranasales (CPN) sin contraste en 10 días (Figura 4 a y 4 b). A las 24 horas de haber iniciado el tratamiento antibiótico la paciente relató presencia sólo de secreción nasal (sin mal olor), ausencia de descarga posteriores. Se observó resolución del cuadro clínico.

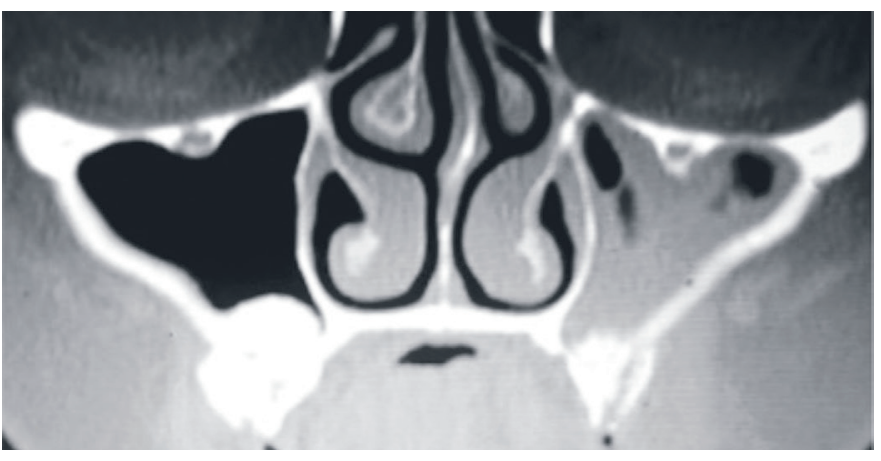

Figura 4. a.TAC de CPN. Se observa nivel hidroaéreo, engrosamiento mucoso en seno maxilar izquierdo y un trayecto hipodenso que comunica con cavidad oral.

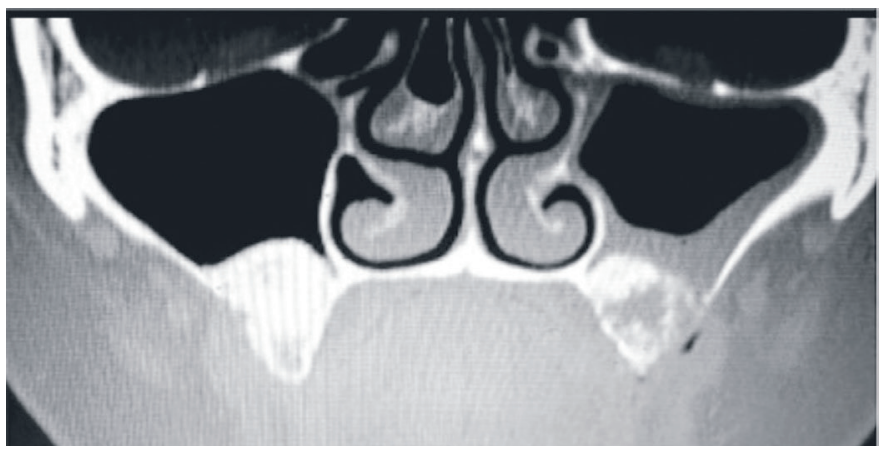

Figura 4. b.TAC de CPN: Se observa nivel hidroaéreo, engrosamiento mucoso y un agujero negro en la porción central del injerto del seno maxilar izquierdo.

Cuatro meses después el otorrinolaringólogo evaluó a la paciente con TAC de CPN. Se observa regresión completa del engrosamiento mucoso y del nivel hidroaéreo, persistiendo en el injerto del lado izquierdo focos de hipodensidad en el espesor de este, y un fino trayecto hipodenso compatible con el cierre natural de la fístula oro-antral. La paciente presentó pérdida parcial del injerto del seno maxilar izquierdo en comparación a su homólogo contralateral. El otorrinolaringólogo otorga el pase médico para la cirugía de instalación de implantes (Figura 5 a y 5 b).

Al octavo mes de la cirugía reconstructiva del maxilar, se instalaron 6 implantes IS-II Active (Neobiotech ${ }^{\circledR}$, Seúl, Corea) de diámetros iguales o superiores a $3.5 \mathrm{~mm}$ y de largos iguales o mayores a $10 \mathrm{~mm}$. La cirugía fue llevada a cabo con éxito, no hubo complicaciones asociadas.

Seis meses después la paciente fue rehabilitada mediante una Prótesis Fija tipo Híbrida, metal-cerámica, directo a plataforma.

A los 3 años de seguimiento clínico e imagenológico, podemos observar una rehabilitación exitosa en términos biomecánicos y estéticos, salud y estabilidad de los tejidos periimplantarios, y ambos senos maxilares sanos (Figura 6 y 7 ).

\section{DISCUSIÓN}

La etiología de las infecciones sinusales postoperatorias responde a dos causas. La primera, a una infección crónica asintomática en los senos, previamente existente y agravada por cambios inflamatorios postoperatorios. La segunda se debe a una comunicación, a través de una perforación, con las bacterias presentes en la flora microbiana de la cavidad oral o procedentes de infecciones periapicales o periodontales, así como también a una contaminación del sitio quirúrgico, del material de injerto, instrumental o membranas. Los pacientes con diagnóstico preoperatorio o síntomas de rinosinusitis aguda o rinosinusitis crónica deben ser sometidos a un tratamiento apropiado y autorización médica antes de la cirugía de elevación de seno. Es prudente remitir al paciente

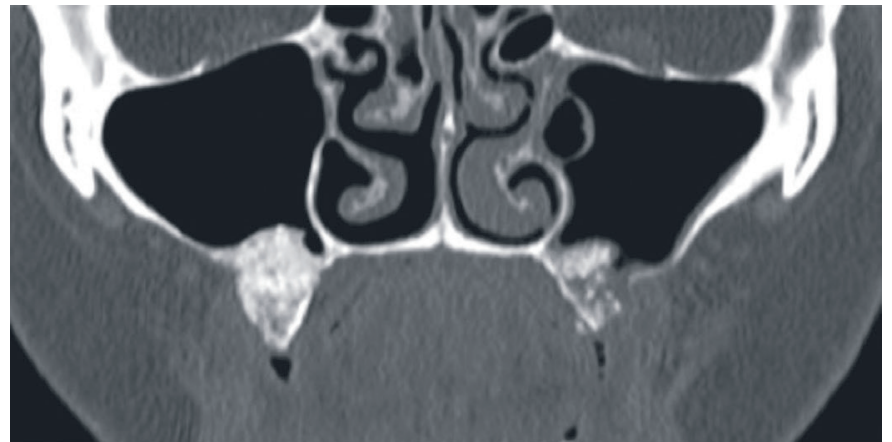

Figura 5. a. TAC de CPN a 4 meses del cuadro clínico. Se observa regresión completa del engrosamiento mucoso y del nivel hidroaéreo, persistiendo en el injerto del lado izquierdo focos de hipodensidad y un fino trayecto hipodenso compatible con el cierre de la fístula oro-antral.

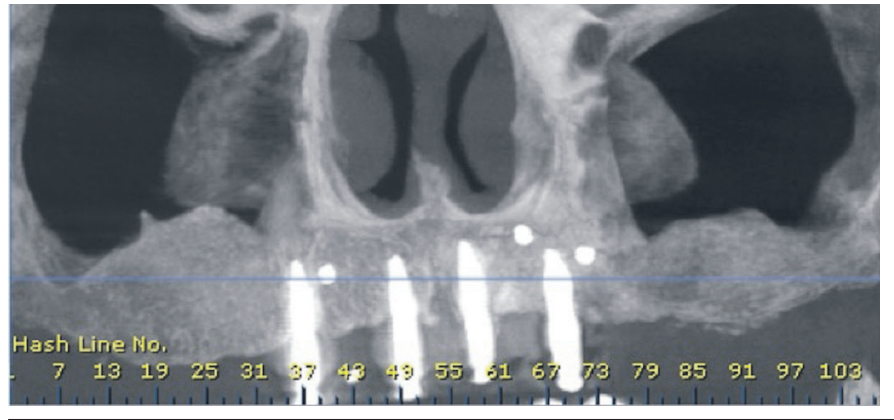

Figura 5. b. CB-CT de control previo a la instalación de implantes, a 6 meses de la resolución del cuadro clínico.

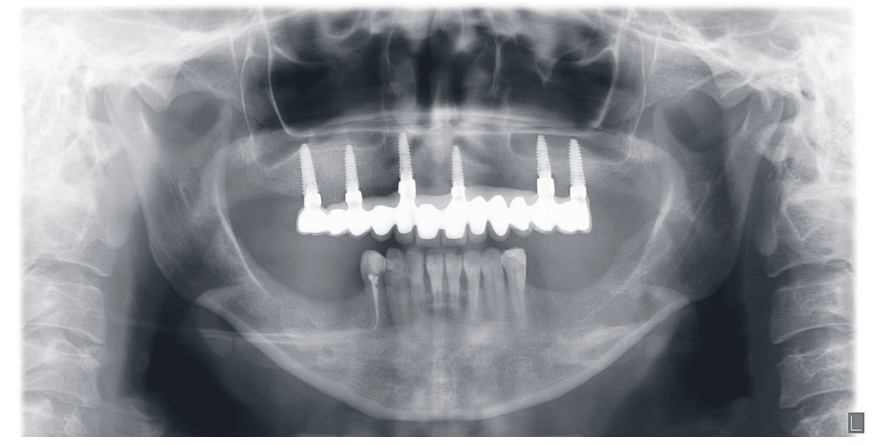

Figura 6. Radiografía panorámica de control a los 3 años del cuadro clínico. Se puede observar estabilidad de los tejidos periimplantarios y ambos senos maxilares sanos.

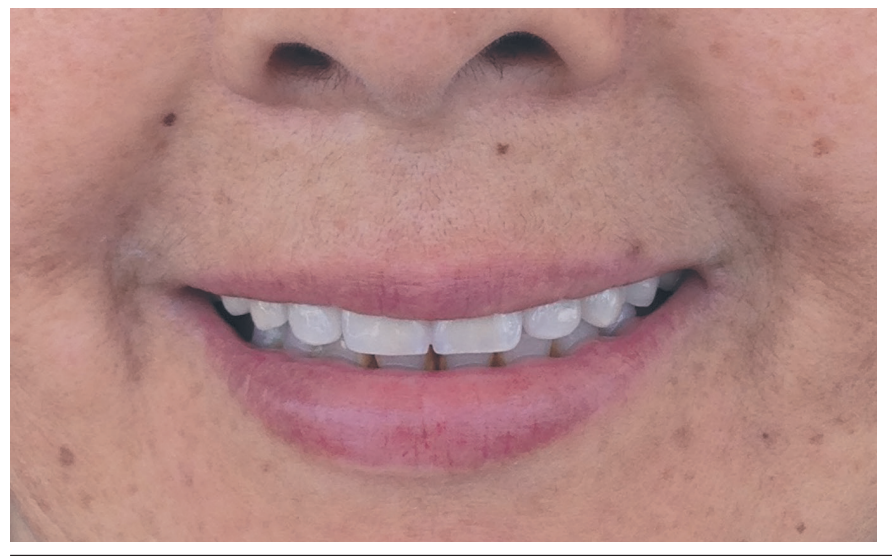

Figura 7. Control a 3 años. Rehabilitación exitosa en términos biomecánicos y estéticos.

a un especialista en otorrinolaringología para diagnosticar y tratar estas condiciones antes de la cirugía ${ }^{(1,6)}$ 
Es esencial un conocimiento acabado de la anatomía del seno maxilar para que la tasa de perforación sea mínima. Estudios retrospectivos reportaron que la tasa de perforación se relaciona principalmente con el espesor de la membrana y en menor grado con la presencia de tabiques intrasinusales. La tasa fue de un $41 \%$ cuando el espesor de la membrana era menor a $1,5 \mathrm{~mm}$ y de un $16,6 \%$ cuando el grosor era mayor. La tasa de perforación fue de un $44,2 \%$ cuando un tabique estaba presente y $35,7 \%$ cuando no se presentaban tabiques ${ }^{(1)}$. En el presente caso clínico, el mínimo espesor de membrana y de la pared lateral del seno maxilar favorecieron la perforación de la membrana al levantar el colgajo.

La Rinosinusitis (RS) es la inflamación sintomática de los senos paranasales y de la cavidad nasal. La RS posterior a cirugía de elevación de seno se ha reportado en un $3-20 \%$ de los $\operatorname{casos}^{(6,7,8)}$, existiendo dentro de este rango las RS no complicadas, que no poseen extensión inflamatoria clínicamente evidente fuera de los senos paranasales y cavidad nasal, en el momento del diagnóstico, es decir, sin compromiso neurológico, oftalmológico y/o afectación de tejidos blandos ${ }^{(9)}$.

La RS puede ser clasificada según su duración en aguda (RSA) si es menor a 4 semanas o en crónica (RSC) en caso de que dure más de 12 semanas, con o sin exacerbaciones agudas. La RSA por su parte, puede ser clasificada según presunta etiología, basada en síntomas y evolución, en rinosinusitis bacteriana aguda (RSBA) o rinosinusitis viral $(\mathrm{RSV})^{(9)}$.

En casos de RSA, el paciente puede presentar descarga nasa purulenta (anterior, posterior, o ambas), obstrucción nasal, dolor facial, presión, sensación de plenitud en el área comprometida y/o cefalea localizada o difusa ${ }^{(9)}$. El cuadro de RSBA es diagnosticado cuando los síntomas o signos de RSA no mejoran dentro de 10 días del inicio de episodio o cuando los síntomas o signos empeoran dentro de los 10 días después de una mejoría inicial ${ }^{(10)}$.

En cuanto al tratamiento de la RSBA se puede indicar terapia antibiótica desde su diagnóstico. Como primera línea de tratamiento e clínico debe prescribir amoxicilina con o sin ácido clavulánico por 10 días para la mayoría de los adultos, si es alérgico a la penicilina prescribir quinolonas bactericidas de tercera o cuarta generación tales como Levofloxacino o Moxifloxacino respectivamente ${ }^{(10,11)}$

Para el manejo sintomático de la RSBA se recomiendan analgésicos, corticoides tópicos intranasales, irrigaciones intranasales con soluciones salinas y/o descongestionantes nasales. Si el paciente no mejora su condición en los primeros 7 días bajo el tratamiento inicial o empeora, el clínico debe reevaluar al paciente para confirmar RSBA, excluir otras causas y/o detectar complicaciones. Si se confirma RSBA y el paciente fue tratado inicialmente con un antibiótico, el clínico debe cambiar el antibiótico a uno de más amplio espectro(6,11).

En relación con la infección del injerto, los síntomas y signos más comunes pueden incluir sensibilidad, obstrucción nasal, dolor, edema, presencia de fístula oro-antral, descarga purulenta, dehiscencia de colgajo y supuración. La presión intrasinusal aumentada puede ser un factor secundario que puede generar un bloqueo del drenaje del seno. La sintomatología puede aparecer tempranamente posterior a la intervención (dentro de dos semanas) o luego de unos meses. El aspecto típico de una infección postoperatoria se puede apreciar en el TAC como un "agujero negro" en la porción central del injerto(1,12).

Las bacterias más comúnmente aisladas de los senos maxilares de pacientes adultos con RSBA son Streptococcus pneumoniae $(20 \%$ $43 \%)$, Haemophilus influenzae (22\%-35\%) y Moraxella catarrhalis $(2 \%$ $10 \%)$. $(10,11)$ Estudios recientes han reportado una resistencia de $S$ pneumoniae a la penicilina en rangos de 25 a $50 \%$, a trimetropina y sulfametoxazol (TMP/SMX) de $43.2 \%$; a macrólidos de $32.5 \%$; a doxiciclina de $21.7 \%$; a clindamicina, $10.8 \%$; y ofloxacin, $2.7 \%$. La producción de ß-lactamasas de $H$ influenzae y $M$ catarrhalis, han sido reportadas en $40 \%$ y $98 \%$, respectivamente ${ }^{(13)}$.

Debido a que en ensayos clínicos aleatorizados (ECA) no se han encontrado diferencias significativas en la tasa de respuesta de diversos regímenes antimicrobianos para la RSBA, la elección del tratamiento antimicrobiano se basa principalmente en; la prevalencia de patógenos respiratorios en la comunidad, el espectro antimicrobiano (incluyendo $S$. Pneumoniae resistente a la penicilina, $H$. Influenzae y $M$. Catarrhalis productores de ß-lactamasas), el costo, la dosificación y los efectos adversos $^{(11)}$.

En el presente caso clínico fracasó el tratamiento antibiótico empírico inicial, por lo cual se consideró la posibilidad de resistencia bacteriana. Como régimen de segunda línea, se eligió un antibiótico con un espectro más amplio de actividad, de un grupo diferente y con actividad contra $S$. Pneumoniae resistente a la penicilina, $H$. Influenzae productor de ß-lactamasa y otros patógenos respiratorios que producen ß-lactamasas ${ }^{(11)}$. Por lo que se cambió la terapia antibiótica a Moxifloxacino, 1 comprimido de $400 \mathrm{mg}$ al día por 10 días, con el cual se consiguió la resolución del cuadro clínico.

Las fluoroquinolonas respiratorias (tanto levofloxacino como moxifloxacino) han permanecido altamente activas contra todos los patógenos respiratorios comunes, incluyendo S. Pneumoniae resistente a la penicilina, $H$. Influenzae y $M$. Catarrhalis productores de ß-lactamasas. Sin embargo, las fluoroquinolonas respiratorias no fueron superiores a los antibióticos ß-lactámicos en el tratamiento de la RSBA en 8 ECA. El tratamiento con ß-lactámicos proporcionó una eficacia comparable en la resolución clínica de los síntomas en comparación con las fluoroquinolonas, sin costo adicional ni efectos adversos ${ }^{(11)}$.

En la actualidad, las fluoroquinolonas respiratorias deben reservarse para aquellos pacientes que no han respondido a los agentes de primera línea, para aquellos con antecedentes de alergia a la penicilina, y como terapia de segunda línea para pacientes con riesgo de infección por $S$. Pneumoniae resistente a la penicilina. Las fluoroquinolonas se asocian a una variedad de efectos adversos que incluyen; a nivel del sistema nervioso central (convulsiones, cefaleas, mareos, trastornos del sueño), neuropatía periférica, fotosensibilidad con erupción cutánea, trastornos de la homeostasis de la glucosa (hipoglicemia e hiperglicemia), prolongación del intervalo QT, disfunción hepática, y riesgo de complicaciones en el sistema musculo esqueletal ${ }^{(11)}$

En el 2007, Arrieta y cols., evaluaron en un estudio multicéntrico la eficacia entre Moxifloxacino $400 \mathrm{mg} 1 \mathrm{vez}$ al día por 7 días y Amoxicilina + Ác. clavulánico 500/125 mg 3 veces al día por 10 días para el tratamiento de la RSBA en adultos. Al comparar ambos fármacos la respuesta clínica y bacteriológica fueron equivalentes, no obstante, el moxifloxacino fue más cómodo en cuanto a número de dosis y tiempo de administración ${ }^{(14)}$

Frente a una infección postoperatoria (infección del injerto y sinusal) como la presentada en el caso hay que considerar iniciar un tratamiento antibiótico en el momento adecuado para impedir el agravamiento del cuadro clínico o un cambio de esquema en caso de resistencia antimicrobiana. En este caso fue clave el manejo multidisciplinario para conseguir la resolución total del cuadro.

\section{CONCLUSIONES}

Actualmente la cirugía de elevación de seno maxilar se considera como la técnica de aumento óseo más predecible. Sin embargo, no está exenta de complicaciones las cuales deben ser manejadas adecuadamente. Es necesario confirmar su presencia rápidamente, evaluar la gravedad y los factores de riesgos involucrados, decidir el tipo o maniobras de tratamiento, y considerar la necesidad de derivación a otros especialistas en caso de ser necesario. Hay que considerar que una excesiva pérdida del injerto podría inhabilitar la inserción de implantes, o podría comprometer la tasa de sobrevida de estos. En la presentación de este caso clínico rehabilitado con 3 años de seguimiento, la utilización de Moxifloxacino $400 \mathrm{mg} 1 \mathrm{vez}$ al día por 10 días fue eficaz frente a la previa utilización de amoxicilina + ácido clavulánico, $875 \mathrm{mg} / 125 \mathrm{mg}$, cada 12 horas, por 10 días, en la resolución de la RSBA posterior a la cirugía de elevación de seno maxilar, la cual tuvo como complicación intraoperatoria la perforación de la mucosa sinusal.

\section{DECLARACIÓN DE CONFLICTO DE INTERÉS Y FUENTE DE FINANCIAMIENTO}

Los autores declaran que no tienen ningún conflicto de intereses, ni asociación o vinculación con alguna de las marcas comerciales utilizadas o nombradas en este estudio.

\section{RESPONSABILIDADES ÉTICAS}

Protección de personas y animales. Los autores declaran que para esta investigación no se han realizado experimentos en seres humanos ni en animales.

Confidencialidad de los datos. Los autores declaran que han seguido los protocolos de su centro de trabajo sobre la publicación de datos de pacientes.

Derecho a la privacidad y consentimiento informado. Los autores han obtenido el consentimiento informado de los pacientes y/o sujetos referidos en el articulo. Este documento obra en poder del autor de correspondencia. 


\section{BIBLIOGRAFÍA}

1. Froum S. Dental implant complications. Etiology, prevention and treatment, Oxford: Wiley-Blackwell publishing; 2010.

2. Wang $H$, Katranji A. ABC sinus augmentation classification. Int J Periodontics Restorative Dent. 2008;28(4):383-389.

3. Zimmo N, Insua A, Sinjab K, Chan H, Shaikh L, Wang H. Impact of sex, age, and season on sinus membrane thickness. Int J Oral Maxillofac Implants. 2018;33(1):175-180

4. Lin $\mathrm{Y}$, Yang $\mathrm{Y}$, Wen $\mathrm{S}$, Wang $\mathrm{H}$. The influence of sinus membrane thickness upon membrane perforation during lateral window sinus augmentation. Clin Oral Implants Res. 2016;27(5):612-617.

5. Pikos M. Maxillary sinus membrane repair: update on technique for large and complete perforations. Implant Dent. 2008;17(1):24-31.

6. Rosenfeld R, Piccirillo J, Chandrasekhar S, Brook I, Kumar K, Kramper M, et al. Clinical practice guideline (update): adult sinusitis executive summary. Otolaryngol Head Neck Surg. 2015;152(4): 598-609.

7. Urban I, Nagursky H, Church C, Lozada J. Incidence, diagnosis, and treatment of sinus graft infection after sinus floor elevation: a clinical study. Int J Oral Maxillofac Implants. 2012;27(2):449-457.

8. Moreno Vazquez J, Gonzalez de Rivera A, Gil H, Mifsut R. Complication rate in 200 consecutive sinus lift procedures: guidelines for prevention and treatment. Oral Maxillofac Surg. 2014;72(5):892-901.
9. Rosenfeld R, Piccirillo J, Chandrasekhar S, Brook I, Ashok Kumar K, Kramper $\mathrm{M}$, et al. Clinical practice guideline (update): adult sinusitis. Otolaryngol Head Neck Surg. 2015 Apr;152(2 Suppl):S1-S39.

10. Chow A, Benniger M, Brook I, Brozek J, Goldstein E, Hicks L, et al. IDSA clinical practice guideline for acute bacterial rhinosinusitis in children and adults. Clin Infect Dis. 2012;54(8):72-112.

11. Johnson T, Lincicum A. Management of wound infection and acute bacterial rhinosinusitis after sinus elevation surgery: a case report. Clin Adv Periodontics. 2018;8(2):54-60

12. Schwartz-Arad D, Herzberg R, Dolev E. The prevalence of surgical complications of the sinus graft procedure and their impact on implant survival, J Periodontol. 2004;75(4):511-16

13. Anon J, Jacobs M, Poole M, et al. Antimicrobial treatment guidelines for acute bacterial rhinosinusitis. Sinus and allergy health partnership. Otolaryngol Head Neck Surg 2000;123:5-31.

14. Arrieta J, Galgano A, Sakano E, et al. Moxifloxacin vs amoxicillin/clavulanate in the treatment of acute sinusitis. Am J Otolaryngol Head Neck Med Surg. 2007;28:78-82. 